\title{
Systemic lambda light-chain deposition presenting with predominant cardiac involvement
}

\author{
M.J. Garton, S. Walton and S.W.B. Ewen ${ }^{1}$
}

Department of Cardiology, Aberdeen Royal Infirmary, and ${ }^{1}$ Department of Pathology, Medical School, University of Aberdeen, Foresterhill, Aberdeen, UK

\begin{abstract}
Summary: An 82 year old woman with suspected Bence Jones myeloma developed intractable fluid retention presumed secondary to cardiac failure. In addition she experienced angina pectoris, and required permanent cardiac pacing for symptomatic sinus bradycardia. Postmortem studies revealed prominent myocardial and renal deposits of lambda light-chains which were Congo Red negative, and had a non-fibrillar ultrastructure. Non-amyloidotic light-chain deposition is uncommon, and a rare cause of cardiac disease. Previous work regarding possible pathogenetic mechanisms, clinical and laboratory features and treatment is reviewed.
\end{abstract}

\section{Introduction}

Systemic deposition of free immunoglobulin lightchains can cause local tissue injury. Deposits may be amyloidotic or non-amyloidotic, and both forms may cause similar organ dysfunction. We describe a patient with cardiac symptoms due to non-amyloidotic deposition of lambda light-chains in the myocardium.

\section{Case report}

A 82 year old Caucasian woman was admitted to hospital with a 10 day history of breathlessness, ankle swelling and intermittent dizziness. She had suffered angina pectoris for 5 years, and latterly developed signs of cardiac failure responsive to diuretics. On examination she had a pulse of $54 /$ minute and blood pressure of $155 / 65 \mathrm{mmHg}$. The jugular venous pressure was not elevated, but there was bilateral pitting oedema. Auscultation revealed soft ejection systolic and early diastolic murmurs.

Chest radiography was normal and electrocardiography showed a sinus bradycardia with poor $r$ wave progression. Serum urea and electrolytes and full blood count were normal, and the erythrocyte sedimentation rate was $17 \mathrm{~mm} /$ hour. The serum albumin was only mildly depressed at $36 \mathrm{~g} / 1$ (nor-

Correspondence: M.J. Garton, M.B., B.S., M.R.C.P., Department of Rheumatology, City Hospital, Urquhart Road, Aberdeen AB9 8AU, UK.

Accepted: 14 December 1992 mal range 37-49 $\mathrm{g} / \mathrm{l}$ ) despite marked proteinuria $(5,340 \mathrm{mg} / \mathrm{l})$. Monoclonal lambda light-chaing were detected in the urine but not the seruro Forty-eight hour Holter monitoring showed persis tent sinus bradycardia with intermittent left bund branch block. Echocardiography revealed trivial aortic regurgitation only. Increased diuretic therapy reduced the peripheral oedema, and her dizziness and breathlessness were relieved by a temporary, and then permanent, pacemaker.

Increasing breathlessness necessitated readmission 2 months later. There was marked peripheral oedema and her jugular venous pressure was elevated. Urinalysis again showed heavy proteinuria. Serum biochemistry was unremarkable although immunoglobulin levels were low; an underlying Bence Jones myeloma was suspected, and the possibility of cardiac amyloidosis considered. Repeat electrocardiography, echocardiography and chest radiography were unchanged. Congo Red staining of a rectal biopsy was negative. A MUGA (multigated acquisition) scan was normal (left ventricular ejection fraction $60 \%$ ) and a technetium pyrophosphate myocardial scan unremarkable. Left and right heart catheterization were performed. Trivial aortic regurgitation and minimal coronary disease were identified. Left ventricular contraction was mildly dyskinetic secondary to pacing but otherwise normal. Ventricular filling pressures were normal although the left ventricular pressure trace suggested a 'dip and plateau' pattern. Pulmonary artery and capillary wedge pressures were also normal. The patient's condition 
gradually deteriorated, her serum albumin fell to $30 \mathrm{~g} / 1$ and despite aggressive diuretic therapy, the patient died a month later.

She had previously donated her body to the University of Aberdeen Medical School and after embalming, organ samples were obtained from the liver, spleen, kidneys and myocardium. Light microscopy (haematoxylin and eosin) revealed well-preserved tissue architecture throughout. The renal biopsy showed features of moderate nodular glomerulosclerosis and all sections were Congo Red negative. However, when stained with thioflavine-T, prominent amorphous extracellular deposits were seen in the myocardium, kidneys and spleen. The myocardial deposits were found in an interstitial and perivascular distribution (Figure 1), whilst the renal deposits were concentrated in the glomeruli with faint peritubular staining (Figure 2). Paraffin-embedded sections of myocardium and kidney were prepared for electron microscopy. Electron-dense deposits with a mixed granular and fibrillar substructure (Figure 3) were seen in a similar distribution. Indirect immunoperoxidase staining for kappa and lambda light-chains was negative. The rectal biopsy was re-examined and stained positively with anti-lambda (but not antikappa) antiserum. Finally, radiographs were reviewed postmortem, and showed generalized osteopenia but no lytic bone deposits.

\section{Discussion}

The detection of free monoclonal immunoglobulin light-chains in urine or serum implies disorganized antibody synthesis amongst cells of B-lymphocyte lineage. An underlying plasma cell dyscrasia or lymphoproliferative disease is often responsible but in a significant minority no malignancy is detectable. In this case a Bence Jones myeloma was likely but not formally demonstrated by marrow examination pre- or postmortem.

Light-chains are poorly soluble proteins and may cause tissue injury by a variety of mechanisms. ${ }^{1}$ Obstructive nephropathy due to precipitation of light-chains within distal tubules is well recognized in Bence Jones myeloma, ${ }^{2}$ and they may also be directly toxic to proximal tubular epithelium. ${ }^{3}$ Light-chains may also form extracellular deposits which may be either amyloidotic or non-amyloidotic in appearance. Amyloidotic lightchain deposits usually contain lambda-class lightchains, are Congophilic, and have a fibrillar appearance on electron microscopy. Non-amyloidotic light-chain deposits were first reported in renal tissue in $1973,{ }^{4}$ and similar systemic deposits were described in 1976..$^{5}$ These latter deposits typically consist of kappa-class light-chains, are Congophobic (although often thioflavine-T

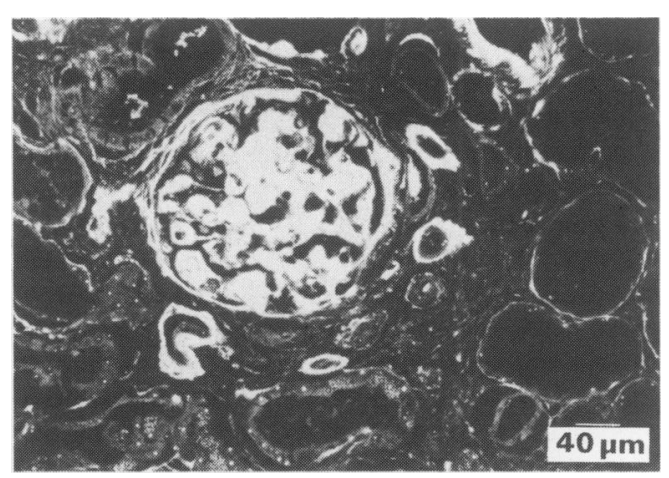

Figure 1 Myocardial tissue displays prominent interstitial and perivascular deposits of amorphous fluorescent material. Thioflavine-T.

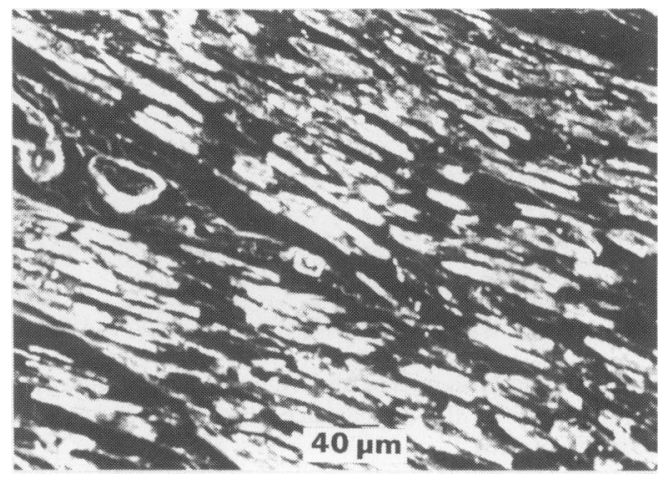

Figure 2 Renal tissue shows amorphous fluorescent deposits in the mesangium and peritubular regions. Thioflavine-T.

positive), and usually have a finely granular ultrastructure, although occasional fibrillar areas may be seen. ${ }^{6,7}$ This deposition pattern has also been termed 'light-chain deposition disease' but this is perhaps not ideal as extracellular light-chain deposition represents a pathogenetic mechanism rather than a discrete disease entity.

It is unclear why some monoclonal light-chains form non-amyloidotic deposits while others form classical amyloidotic precipitates. Biosynthetic studies in several patients with non-amyloidotic deposits have suggested abnormalities of lightchain length and glycosylation. ${ }^{8}$ Furthermore non-amyloidotic light-chain deposits lack the amyloid-P component which may be essential for amyloidogenesis. ${ }^{9}$ Occasionally both forms of deposit occur in the same patient. ${ }^{10}$

The clinical manifestations of non-amyloidotic light-chain deposition appear to be similar to those of light-chain amyloidosis. Most patients present with renal failure and non-selective proteinuria. ${ }^{6,11}$ The liver ${ }^{12}$ and heart ${ }^{13}$ may also be involved and, 


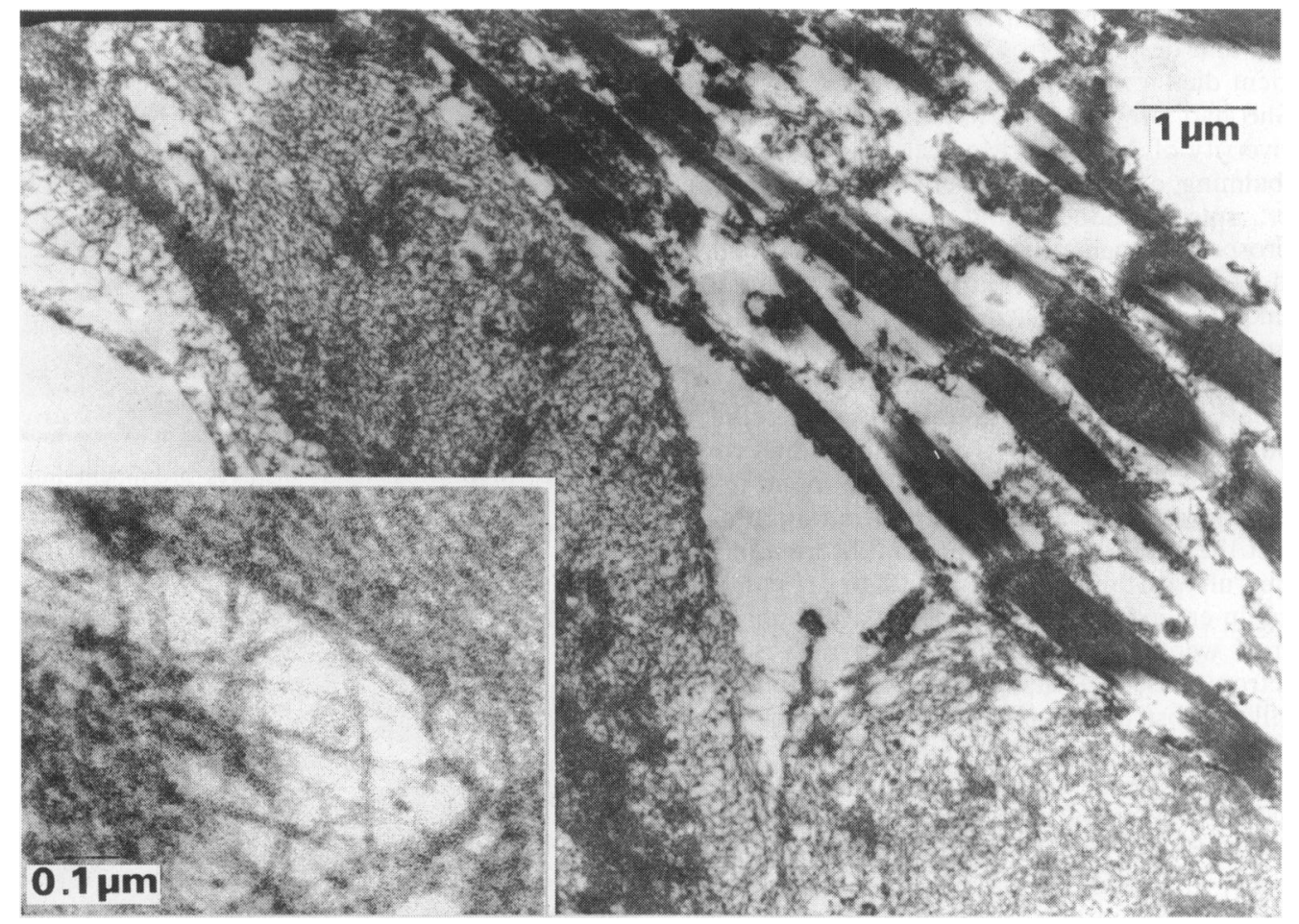

Figure 3 Electron micrograph of myocardial tissue displaying an interstitial deposit of electron-dense material with a granular and fibrillar appearance. Inset: Higher power view of similar material found in the glomerular mesangium of the same patient.

although heart failure is not uncommon, ${ }^{7,13,14}$ it has never previously been reported to our knowledge with lambda light-chain deposition. Detailed investigations in several subjects with non-amyloidotic light-chain deposition ${ }^{14-16}$ suggest features similar to cardiac amyloidosis. ${ }^{17}$ In the latter the primary defect is diastolic failure with variable systolic impairment, and ventricular filling pressures are usually elevated, particularly on the left. Rapid early diastolic filling with abrupt cessation of filling in mid-diastole is reflected in the characteristic 'dip and plateau' left ventricular pressure waveform. In our patient cardiac catheterization was unremarkable apart from an abnormal left ventricular pressure tracing, although the filling pressures may have been normalized by prior diuretic therapy. Although she also had heavy proteinuria her serum albumin was initially well preserved and at this time her fluid retention was felt to be due to a restrictive cardiac defect. However, in the terminal phase of her illness it seems that myocardial function was otherwise well preserved and that renal involvement was the cause of her death.

Other cardiac complications of non-amyloidotic light-chain deposition include arrhythmias ${ }^{13,18}$ and myocardial infarction. ${ }^{7,16,19}$ Sinus bradycardia and angina pectoris have been reported rarely $y^{7,16}$ and in both patients kappa light-chain deposits were identified. Intercellular light-chain deposits probably reduce myocardial compliance and impair tissue oxygenation, while deposits in intramyocardial arterioles may restrict tissue perfusion.

A combination of hypogammaglobulinaemia with either nephropathy, neuropathy or cardiomyopathy should suggest light-chain deposition. ${ }^{13}$ Non-amyloidotic deposits probably occur as often as light-chain amyloidosis but are diagnosed less frequently. Accurate diagnosis rests upon immunohistological and/or ultrastructural ${ }^{9,20}$ examination of biopsies from involved organs. Immunohistochemistry is not always positive ${ }^{7}$ and failure of immunological staining may become more prevalent with ageing of the deposits ${ }^{21}$ which may explain the present findings. However, the embalming process may have reduced the accessibility of antigenic binding sites on the deposited light-chains compared to those in the rectal biopsy.

As in light-chain amyloidosis, the management of non-amyloidotic light-chain deposition is unsatisfactory. There is some evidence that appropriate cytotoxic therapy may benefit those patients who have an underlying myeloma, and even those 
who do not. ${ }^{22}$ However, caution may be justified in the presence of cardiac involvement. Cardiotoxic agents such as doxorubicin may carry an increased risk in patients with pre-existing cardiac disease, , $^{23,24}$ and a case of fatal heart failure was reported recently in a subject with cardiac amyloidosis after a single dose of this drug. ${ }^{25}$

Treatment of specific cardiac symptoms is also contentious. Diuretics should be used cautiously in heart failure as excessive reductions in filling pressures could reduce cardiac output and cause hypotension. The treatment of bradyarrhythmias is also problematic. Poor ventricular compliance makes atrial transport relatively more important and, without an atrial pacemaker, cardiac output may actually fall.

\section{Acknowledgements}

The authors would like to thank Dr L.E. Murchison, Dr W.G. Skene and Dr A. Dawson for their valuable assistance. We also thank Dr F.J. Gilbert and Mrs K. Reynolds of the Radiology Department, Foresterhill.

\section{References}

1. Solomon, A., Weiss, D.T. \& Kattine, A.A. Nephrotoxic potential of Bence Jones proteins. N Engl J Med 1991, 324: $1845-1851$.

2. Sanders, P.W. \& Booker, B.B. Pathobiology of cast nephropathy from human Bence Jones proteins. $J$ Clin Invest 1992, 89: 630-639.

3. Sanders, P.W., Herrera, G.A., Lott, R.L. \& Galla, J.H. Morphologic alterations of the proximal tubules in light chain-related disease. Kidney Int 1988, 33: 881-889.

4. Antonovych, T.T., Lin, R.C. \& Mostofi, F.K. Multiple myeloma: ultrastructural and immunofluorescent findings in the kidney (Abstract). Lab Invest 1974, 30: 370A.

5. Randall, R.E., Williamson, W.C., Jr, Mullinax, F., Tung, M.Y. \& Still, W.J.S. Manifestations of systemic light chain deposition. Am J Med 1976, 60: 293-299.

6. Gallo, G.R., Feiner, H.D., Katz, L.A. et al. Nodular glomerulopathy associated with nonamyloidotic kappa light chain deposits and excess immunoglobulin light chain synthesis. Am J Pathol 1980, 99: 621-644.

7. Toyoda, M., Kajita, A., Kita, S., Osamura, Y. \& Shinoda, T. An autopsy case of diffuse myelomatosis associated with systemic kappa light chain deposition disease (LCDD). A pathoanatomical, immunohistochemical and immunobiochemical study. Acta Pathol Jpn 1988, 38: 479-488.

8. Preud'homme, J.-L., Morel-Maroger, L., Brouet, J.C. et al. Synthesis of abnormal immunoglobulins in lymphoplasmacytic disorders with visceral light chain deposition. Am J Med 1980, 69: 703-710.

9. Gallo, G., Picken, M., Frangione, B. \& Buxbaum, J. Nonamyloidotic monoclonal immunoglobulin deposits lack amyloid P component. Mod Pathol 1988, 1: 453-456.

10. Jacqout, C., Saint-Andre, J.-P., Touchard, G. et al. Association of systemic light-chain deposition disease and amyloidosis: a report of three cases with renal involvement. Clin Nephrol 1985, 24: 93-98.

11. Tubbs, R.S., Gephardt, G.N., MacMahon, J.T., Hall, J.M., Valenzuela, R. \& Vidt, D.G. Light chain nephropathy. Am J Med 1981, 71: 263-269.

12. Bedossa, P., Fabre, M., Paraf, F., Martin, E. \& Lemaigre, G. Light chain deposition disease with liver dysfunction. Hum Pathol 1988, 19: 1008-1014.

13. Buxbaum, J.N., Chuba, J.V., Hellman, G.C., Solomon, A. \& Gallo, G.R. Monoclonal immunoglobulin deposition disease: light chain and light and heavy chain deposition disease and their relation to light chain amyloidosis. Clinical features, immunopathology and molecular analysis. Ann Intern Med 1990, 112: 455-464.
14. Laurent, M., Toulet, R., Ramee, M.P., Legrand, D., Le Normand, J.P. \& Lelguen, C. Light chain disease and terminal cardiomyopathy. Arch Mal Couer 1985, 78: 943-946.

15. McAllister, H.A., Jr, Seger, J., Bossart, M. \& Ferrans, V.J. Restrictive cardiomyopathy with kappa light chain deposits in myocardium as a complication of multiple myeloma. Histochemical and electron microscopic observations. Arch Pathol Lab Med 1988, 112: 1151-1154.

16. Peng, S.K., French, W.J., Cohen, A.H. \& Fausel, R.E. Light chain cardiomyopathy associated with small-vessel disease. Arch Pathol Lab Med 1988, 112: 844-846.

17. Howard Swanton, R., Brooksby, I.A.B., Davies, M.J., Coltart, D.J., Jenkins, B.S. \& Webb-Peploe, M.M. Systolic and diastolic ventricular function in cardiac amyloidosis. Studies in six cases diagnosed with endomyocardial biopsy. Am J Cardiol 1977, 39: 658-664.

18. Ganeval, D., Noël, L.H., Droz, D. \& Leibowitch, J. Systemic lambda light-chain deposition in a patient with myeloma. $\mathrm{Br}$ Med J 1981, 282: 681-683.

19. Staros, E. \& Katz, S.M. Myocardial necrosis in light chain deposition. Am Heart J 1985, 110: 1295-1296.

20. Gallo, G. \& Buxbaum, J. Monoclonal immunoglobulin deposition disease: immunopathologic aspects of renal involvement. In: Minetti, L., D’Amico, G. \& Ponticelli, C. (eds) The Kidney in Plasma Cell Dyscrasias. Kluweer Academic Publishers, Dordrecht, 1988, pp. 171-181.

21. Silver, M.M., Hearn, S.A., Ritchie, S. et al. Renal and systemic kappa light chain deposits and their plasma cell origin identified by immunoelectron microscopy. Am J Pathol 1986, 122: 17-27.

22. Ganeval, D., Noël, L.H., Preud'homme, J.-L., Droz, D. \& Grunfeld, J.-P. Light-chain deposition disease: its relation with AL-type amyloidosis. Kidney Int 1984, 26: 1-9.

23. Von Hoff, D.D., Layard, M.W., Basa, P. et al. Risk factors for doxorubicin-induced congestive heart failure. Ann Intern Med 1979, 91: 710-717.

24. Schwartz, R.G., McKenzie, W.B., Alexander, J. et al. Congestive heart failure and left ventricular dysfunction complicating doxorubicin therapy. Am J Med 1987, 82. $1109-1118$.

25. Devoy, M.A.B. \& Tomson, C.R.V. Fatal cardiac failure after a single dose of doxorubicin in myeloma-associated cardiac amyloid. Postgrad Med J 1992, 68: 69. 